\title{
KIẾN THỨC VÊ PHÒNG TRÁNH NHIỄM ĐộC CHÌ CHO TRẺ EM TẠI MộT LÀNG NGHỀ THUộC TỈNH BẮC NINH
}

\section{TÓM TẮT}

Mục tiêu: Tìm hiểu kiến thức về phòng tránh nhiễm độc chì cho trẻ em của người dân tại một làng nghề thuộc tỉnh Bắc Ninh. Phương pháp nghiên cứu: 212 đối tượng (165 người chăm sóc trẻ và 47 trẻ em (10-14 tuổi)) được điều tra theo mẫu phiếu có sẵn về mức đô độc hai của chì đối với sức khỏe; nhóm đối tượng bị ảnh hưởng nhiều nhất khi bị nhiễm chì; biểu hiển nhiễm đôc chì ở trẻ; nguồn phơi nhiễm chì; con đường phơi nhiễm chì; biện pháp phòng tránh nhiếm chì cho trẻ. Kết quả: điểm kiến thức trung bình của nhóm người chăm sóc trẻ là $3,7 \pm 1,2$ điểm, của nhóm

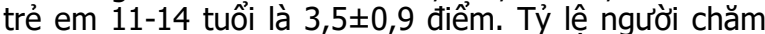
sóc trẻ có kiến thức đạt chiếm $64,2 \%$, tỷ lệ này ở nhóm trẻ em 11-14 tuổi tham gia nghiên cứu là 46,8\%. Kết luận: người dân tại một làng nghề thuộc tỉnh Bắc Ninh đã có một số kiến thức cơ bản về phòng chống nhiếm độc chì cho trẻ nhưng còn hạn chế.

Tư khoá: Kiến thức, nhiếm độc chì, trẻ em, làng nghề, Bắc Ninh

\section{SUMMARY \\ KNOWLEDGE OF CHILDREN TO PREVENT LEAD POISONING IN ONE VILLAGE IN BAC NINH PROVINCE}

Objectives: to evaluate people's knowledge on prevention of lead poisoning in a craft village of Bac Ninh province. Methods: 212 subjects (165 caregivers and 47 children (10-14 years old)) were investigated by questionnaire about lead toxic to health; target groups most affected by lead exposure; manifestations of lead poisoning in children; source of lead exposure; pathway of lead exposure; lead preventive measures for children. Results: The average score of caregivers' s knowledge goup on prevention of lead poisoning was $3.7 \pm 1.2$ points and that among children group from 11-14 years old was $3.5 \pm 0.9$ points. Percentage of caregivers's knowledge score at pass level was $64.2 \%$, and that among the children's group from 11-14 years old was $46.8 \%$. Conclusion: People in a craft village in Bac Ninh province have some basic knowledge about prevention of lead poisoning for children, but they are still limited.

Keywords: Knowledge, lead poisoning, children, craft villages, Bac Ninh

\section{I. ĐĂT VẤN ĐỀ}

Những vấn đề sức khỏe do ô nhiễm môi trường, do tiếp xúc với hóa chất độc hại, ô nhiễm

\footnotetext{
${ }^{1}$ Viên Sức khỏe nghề nghiêp và Môi trường

Chịu trách nhiệm chính: Nguyễn Đức Sơn

Email: ducson199@gmail.com

Ngày nhận bài: 7.6.2021

Ngày phản biên khoa hoc: 30.7.2021

Ngày duyệt bài: 9.8.2021
}

Nguyễn Đức Sơn ${ }^{1}$, Nguyễn Thu Hà' kim loại nă̆ng,... là mối quan tâm lớn trên thế giới, đặc biệt ở các nước đang phát triển. Theo Tổ chức $Y$ tế thế giới $(W H O)$, chì là một trong mười loại kim loại nặng cần được quan tẩm nhất đối với sức khỏe con người, đặc biệt là trẻ em và phụ nữ trong độ tuổi sinh đẻ. Uớc tính mỗi năm ghi nhận thêm mới khoảng 600.000 trẻ em bị ảnh hưởng trí tuệ và 143.000 trường hợp tử vong do tiếp xúc chì, đặc biệt ở các nước đang phát triển [1], [2].

Trẻ em tại làng nghề có thể có nguy cơ phơi nhiễm chì từ nhiều nguồn khác nhau như từ chì phát sinh trong các hoạt động tái chế sắt, thép; chì trong đồ chơi; chì trong sơn; chì trong thực phẩm, nước uống, không khí bị ô nhiễm chì... Để phòng tránh nhiếm độc chì cho trẻ thì cha, me của trẻ, những người chăm sóc trẻ (NCST) chính và bản thân trẻ phải có kiến thức cơ bản về phòng tránh nhiễm độc chì cho trẻ em

Mục tiêu nghiên cứu: Tìm hiểu kiến thức về phòng tránh nhiếm độc chi cho tré em của người dân tại một làng nghể thuộc tỉnh Bắc Ninh

II. Đốl TƯỢNG VÀ PHƯƠNG PHÁP NGHIÊN CỨU

2.1. Đối tượng nghiên cứu: 212 đối tượng (165 người chăm sóc trẻ và 47 trẻ em (10-14 tuổi)) sống tại một làng nghề thuộc tỉnh Bắc Ninh

\subsection{Phương pháp nghiên cứu}

- Thiết kế nghiên cứu: Nghiên cứu mô tả cắt ngang

- Phương pháp chọn mẫu: chọn ngẫu nhiên đối tượng tham gia nghiên cứu từ danh sách các hộ gia đình từ danh sách hộ gia đình có trẻ từ 314 tuổi đang sống tại làng nghề và tiến hành phỏng vấn trực tiếp đối tượng bằng phiếu phỏng vấn được thiết kế sẵn. Cụ thể:

- Lập danh sách hộ gia đình từ danh sách hộ gia đình có trẻ từ 3- 14 tuổi đang sống tại làng nghề kèm theo địa chỉ hộ gia đình, số trẻ từ 3-14 tuổi của hộ gia đình và họ tên của trẻ.

- Chọn ngẫu nhiên hộ gia đình trong danh sách cho đến khi đủ 212 trẻ từ 3-14 tuổi. Phát giấy mời tham gia nghiên cứu đến tận hộ gia đình. Trường hợp hộ gia đình có nhiều hơn 01 trẻ từ 3-14 tuổi, chọn phỏng vấn 01 người chăm sóc trẻ chính nếu trẻ dưới 10 tuổi và phỏng vấn trực tiếp trẻ từ 10-14 tuổi

- Các chỉ số nghiên cứu

Kiến thức của đối tượng nghiên cứu được đánh giá qua 06 câu hỏi chính:

+ Mức độ độc hại của chì đối với sức khỏe: 
trả lời đúng $\rightarrow$ được 1 điểm.

+ Nhóm đối tượng bị ảnh hưởng nhiều nhất khi bị nhiễm chì: trong câu trả lời có nhóm trẻ em $\rightarrow$ được 1 điểm.

+ Biểu hiện nhiễm độc chì ở trẻ: Liệt kê được $\geq 3$ biểu hiện đúng $\rightarrow$ được 1 điểm

+ Nguồn phơi nhiễm chì cho trẻ: Liệt kê được $\geq 3$ nguồn đúng $\rightarrow$ được 1 điểm.

+ Con đường phơi nhiễm chì cho trẻ: Có 8 con đường được đưa ra, chọn được từ 6 con đường trở lên $\rightarrow$ được 1 điểm.

+ Biện pháp phòng tránh nhiễm chì cho trẻ: Có 07 biện pháp được đưa ra, chọn được được từ 4 biện pháp trở lên $\rightarrow$ được 1 điểm.

$\rightarrow$ Điểm kiến thức tối đa là 06 điểm. Đối tượng được đánh giá là có kiến thức đạt nếu tổng số điểm đạt từ 4 điểm trở lên.

2.3. Đạo đức trong nghiên cứu: tuân thủ đây đủ các vấn đề y đức trong nghiên cứu theo Hội đồng y đức Viện Sức khỏe nghề nghiệp và môi trường - Bộ Y tế phê duyệt

\subsection{Xử lý số liệu}

- Làm sạch thô bằng cách kiểm tra các phiếu trả lời, loại bỏ những phiếu bỏ trống > 50\% thông tin.

- Nhập liệu bằng phân mêm Epidata

- Xử lý số liệu bằng phân mềm SPSS

\section{KẾT QUẢ NGHIÊN CứU}

3.1. Thông tin chung về đối tượng nghiên cứu. Nghiên cứu có sự tham gia của 212 đối tượng, trong đó $77,8 \%$ là NCST và 47 trẻ em từ 10-14 tuổi (sau đây goi tắt là nhóm trẻ em, chiếm 22,2\%). Đa số người tham gia nghiên cứu là nữ (chiếm 89,1\% trong nhóm NCST và 55,3\% trong nhóm tré em) (Hình 3.1). Hình 3.2 cho thâyy phân bố nhóm tuổi của 212 trẻ từ 3-14 tuổi tại các hộ gia đình tham gia nghiên cứu, có $25,9 \%$ trẻ dưới 6 tuổi, 44,3\% trẻ từ $6-10$ tuồi và $29,7 \%$ trẻ từ $11-14$ tuổi.

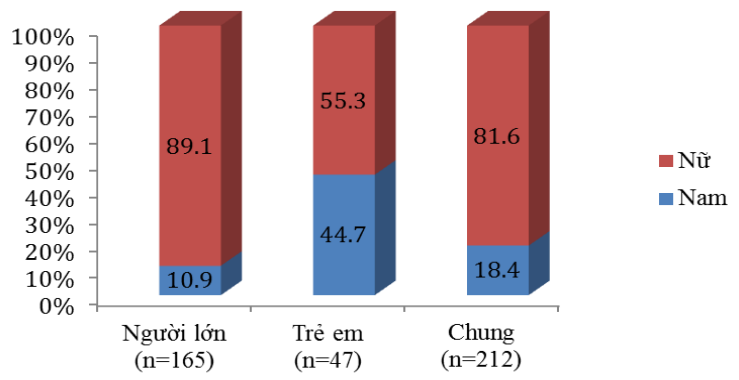

Hình 3. 1. Phân bố giới tính của đôî tượng tham gia nghiên cứu

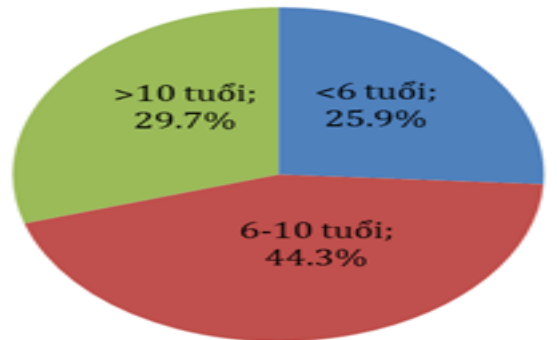

Hình 3. 2. Phân nhóm tuổi của trẻ

\subsection{Kiến thức về phòng tránh nhiễm độc chì cho trẻ em}

Bảng 3. 1. Kiến thức về mức độ độc hại của chi đối với sức khỏe

\begin{tabular}{|c|c|c|c|c|c|c|c|}
\hline \multirow{2}{*}{\multicolumn{2}{|c|}{$\begin{array}{l}\text { Kiến thức về mức độ độc hại của chì đôii } \\
\text { với sức khỏe }\end{array}$}} & \multicolumn{2}{|c|}{$\begin{array}{c}\text { NCST } \\
(n=165)\end{array}$} & \multicolumn{2}{|c|}{$\begin{array}{l}\text { Trẻ em } \\
(n=47)\end{array}$} & \multicolumn{2}{|c|}{$\begin{array}{c}\text { Chung } \\
(n=212)\end{array}$} \\
\hline & & $\mathbf{n}$ & $\%$ & $\mathbf{n}$ & $\%$ & $\mathbf{n}$ & $\%$ \\
\hline \multirow{3}{*}{$\begin{array}{l}\text { Mức độ chì có } \\
\text { thể gây hại } \\
\text { cho sức khỏe }\end{array}$} & Không biết & 38 & 23 & 11 & 23,4 & 49 & 23,1 \\
\hline & Bất kỳ nông độ nào & 99 & 60 & 31 & 66,0 & 130 & 61,3 \\
\hline & Nhiêm chì ở nồng độ cao & 28 & 17 & 5 & 10,6 & 33 & 15,6 \\
\hline \multirow{4}{*}{$\begin{array}{c}\text { Nhóm bị ảnh } \\
\text { hưởng nhiều } \\
\text { nhất khi bị } \\
\text { nhiếm chì }\end{array}$} & Trẻ em & 154 & 93,3 & 39 & 83,0 & 193 & 91,0 \\
\hline & Người già & 43 & 26,1 & 12 & 25,5 & 55 & 25,9 \\
\hline & Người trưởng thành & 15 & 9,1 & 10 & 21,3 & 25 & 11,8 \\
\hline & Phụ nữ có thai & 108 & 65,5 & 29 & 61,7 & 137 & 64,6 \\
\hline
\end{tabular}

Bảng 3.1 cho thấy 23,1\% người không biết nhiếm chì ở mức độ nào thì ảnh hưởng đến sức khỏe; $91 \%$ người cho rằng trẻ em là đối tượng bị ảnh hưởng nhiêuu nhất khi bị nhiễm chì. Trẻ em và phụ nữ có thai là 02 đối tượng được đa sỗ $(64,6 \%)$ người tham gia lựa chọn lựa chọn là 02 nhóm đối tượng bị ảnh hưởng nhiêu nhất khi bị nhiễm chì (Hình 3.3).

Bảng 3.2. Kiến thức về nguồn phơi nhiếm chi cho trẻ

\begin{tabular}{|c|c|c|c|c|c|c|}
\hline \multirow{2}{*}{$\begin{array}{c}\text { Các nguồn phơi nhiêmm chì } \\
\text { cho trẻ em }\end{array}$} & \multicolumn{2}{|c|}{ NCST (n=165) } & \multicolumn{2}{c|}{ Trẻ em $\mathbf{~ ( n = 4 7 ) ~}$} & \multicolumn{2}{c|}{ Chung (n=212) } \\
\cline { 2 - 7 } & $\mathbf{n}$ & $\mathbf{0}$ & $\mathbf{n}$ & $\mathbf{\%}$ & \multicolumn{1}{c|}{$\mathbf{n}$} & $\mathbf{\%}$ \\
\hline Không biết/ Không trả lời & 38 & 23,0 & 19 & 40,4 & 57 & 26,9 \\
\hline Có biết & 127 & 77,0 & 38 & 59,6 & 165 & 73,1 \\
\hline Thực phấm có chì & 88 & 69,3 & 21 & 75,0 & 109 & 70,3 \\
\hline
\end{tabular}




\begin{tabular}{|c|c|c|c|c|c|c|}
\hline Sơn pha chì & 81 & 63,8 & 14 & 50,0 & 95 & 61,3 \\
\hline Nguồn nước nhiêm chì & 67 & 52,8 & 18 & 64,3 & 85 & 54,8 \\
\hline Không khí ô nhiêm chì & 46 & 36,2 & 7 & 25,0 & 53 & 34,2 \\
\hline $\begin{array}{c}\text { Sản xuất, tái chế ắc quy và } \\
\text { chất thải điện tử }\end{array}$ & 28 & 22,0 & 3 & 10,7 & 31 & 20,0 \\
\hline Đồ chơi trẻ em có chì & 22 & 17,3 & 2 & 7,1 & 24 & 15,5 \\
\hline Kế được >3 nguồn nêu trên & 34 & 26,8 & 5 & 17,9 & 39 & 25,2 \\
\hline
\end{tabular}

Bảng 3.2 cho thấy có 127 người tham gia cứu lựa chọn là nguồn nước có chứa chì nghiên cứu trả lời rằng họ có biết về các nguồn $(45,1 \%)$, tiếp đến là không khí ô nhiễm chì phơi nhiếm (chiếm 73,1\%), trong đó nhóm NCST là $77 \%$, nhóm trẻ em là $59,6 \%$. Có nhiều nguồn phơi nhiễm chì được các đối tượng tham gia nghiên cứu chỉ ra, trong đó nguồn phơi nhiểm được đa số người tham gia lựa chọn là thực phẩm chứa chì (70,3\%); tiếp đến là sơn pha chì $(61,3 \%)$ và chỉ có $15,5 \%$ người tham gia đề cập đến đồ chơi có chứa chì.

Có 06 trẻ từ 10-14 tuổi và 22 NCST tham gia không biết hoặc không đưa ra nhận xét về nguiôn phơi nhiễm chì cho chính bản thân trẻ em của gia đình. Trong 41 trẻ từ 10-14 tuổi tham gia trả lời câu hỏi này, có $58,5 \%$ trẻ cho rằng mình không nhiễm chì. Trong 143 NCST tham gia trả lời có $35 \%$ cho rằng con/ cháu họ không bị nhiễm chì. Nguồn phơi nhiễm chì cho chính bản thân trẻ em $(35,3 \%)$ (Hình 3.4).

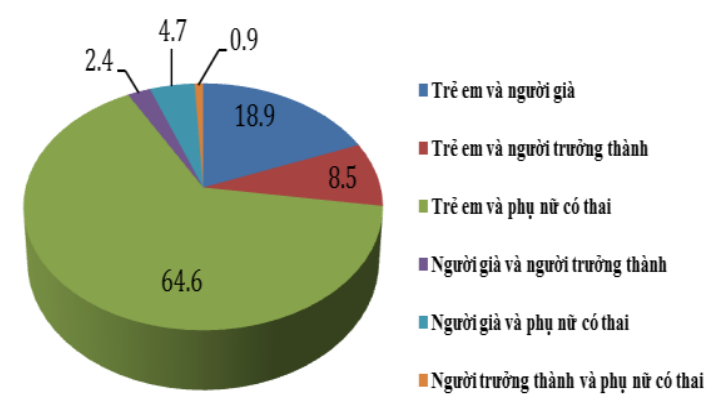

\section{Hình 3. 3. Hai nhóm đôi tượng bị ảnh hưởng nhiều nhất khi bị nhiếm chi} của gia đình được đa số người tham gia nghiên

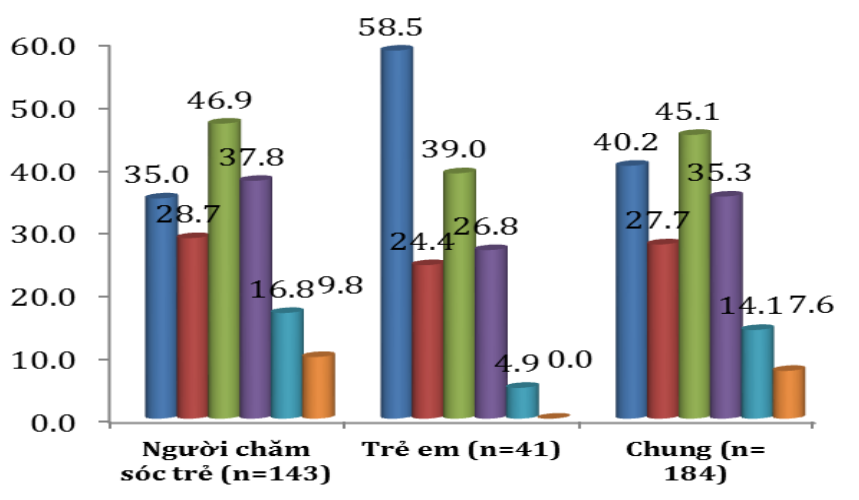

$$
\begin{aligned}
& \text { Trẻ trong gia đình không } \\
& \text { nhiếm chì } \\
& \text { Thực phẩm có chì } \\
& \text { Nguồn nước nhiễm chì } \\
& \text { - Không khí ô nhiễm chì } \\
& \text { Đồ chơi có chì } \\
& \text { - Sản xuất, tái chế ắc quy và } \\
& \text { chất thải điện tử }
\end{aligned}
$$

\begin{tabular}{|c|c|c|c|c|c|c|}
\hline \multirow{2}{*}{$\begin{array}{l}\text { Con đường phơi nhiếm chì } \\
\text { cho trẻ em }\end{array}$} & \multicolumn{2}{|c|}{ NCST $(n=165)$} & \multicolumn{2}{|c|}{ Trẻ em $(n=47)$} & \multicolumn{2}{|c|}{ Chung $(n=212)$} \\
\hline & $\mathbf{n}$ & $\%$ & $\mathbf{n}$ & $\%$ & $\mathbf{n}$ & $\%$ \\
\hline Ān thức ăn có chì & 148 & 90,2 & 47 & 100 & 195 & 92,0 \\
\hline Uống nước có chì & 147 & 89,6 & 46 & 97,9 & 193 & 91,0 \\
\hline Hít phải bụi có chì & 153 & 93,3 & 41 & 87,2 & 194 & 91,5 \\
\hline $\begin{array}{l}\text { Thói quen ngậm, mút đồ chơi, } \\
\text { đồ dưng của trẻ }\end{array}$ & 149 & 90,3 & 41 & 87,2 & 190 & 89,6 \\
\hline $\begin{array}{c}\text { Thói quen chơi lê la dưới sàn } \\
\text { nhà, nền đất của trẻ }\end{array}$ & 135 & 81,8 & 34 & 72,3 & 169 & 79,7 \\
\hline Chì thấm qua da & 114 & 69,5 & 34 & 72,3 & 148 & 69,8 \\
\hline $\begin{array}{c}\text { Từ người làm công việc liên quan } \\
\text { đến chì }\end{array}$ & 113 & 68,5 & 34 & 72,3 & 147 & 69,3 \\
\hline Từ NCST & 111 & 67,3 & 32 & 68,1 & 143 & 67,5 \\
\hline
\end{tabular}

Hình 3.4. Nguồn phơi nhiễm cho bản thân trẻ trong gia đình

Bảng 3.3. Kiến thức về con đường phơi nhiếm chì cho trẻ 
Về con đường phơi nhiễm chì, bảng 3.3 cho thấy trong số 212 người tham gia, đa số lựa chọn con đường ăn, uống thức ăn, nước uống và hít phải không khí bị ô nhiễm chì với tỷ lệ trên $90 \%$; tiếp đến là những thói quen không hợp vệ sinh của trẻ như ngậm, mút đồ chơi, đồ dùng và chơi lê la dưới sàn nhà, nền đất với tỷ lệ tương ứng là $89,6 \%$ và $79,7 \%$.

Về ảnh hưởng của chì đối với sức khỏe trẻ em, có tới $78,8 \%$ trong tổng số 212 người tham gia nghiên cứu không biết các biểu hiện nhiễm độc chì ở trẻ $(79,4 \%$ NCST và $76,6 \%$ trẻ em 10 14 tuổi). Trong câu trả lời của 45 người còn lại, biểu hiện nhiễm độc chì ở trẻ được đa số người biết đển là buồn nôn $(51,1 \%)$ và đau bụng $(48,9 \%)$. Các biểu hiện như nghe kém, học kém, dễ cáu, dễ bị kích thích thì tỳ lệ đối tượng lựa chọn ít hơn. Không có người nào chọn thiếu máu là biểu hiện của nhiễm độc chì (Hình 3.5).

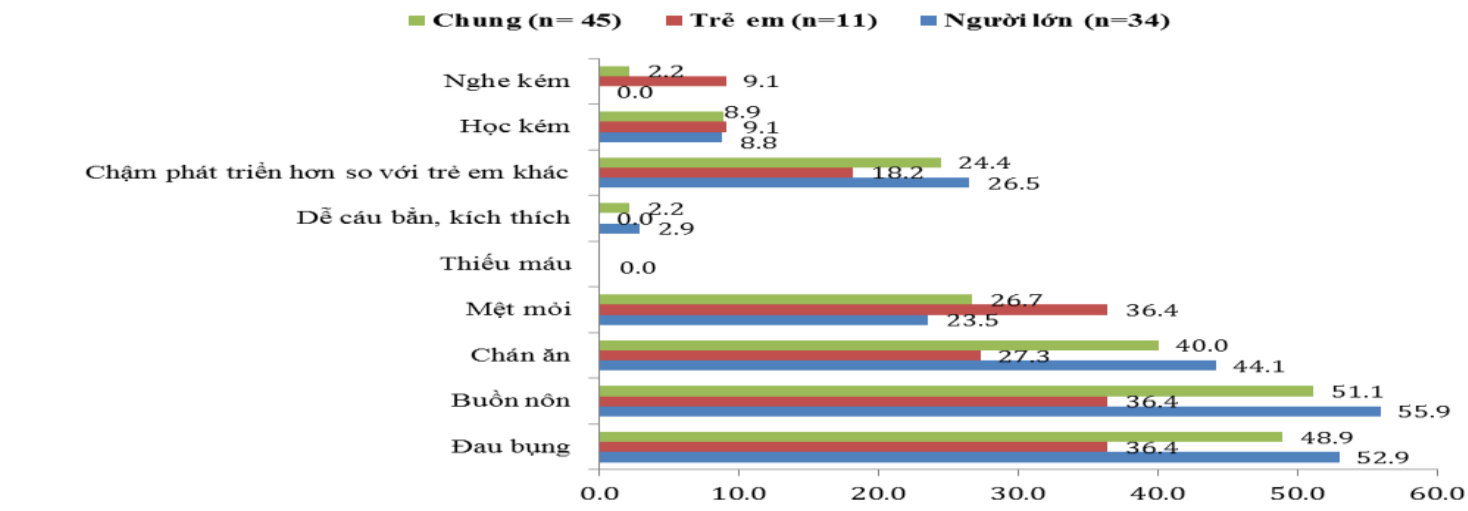

Hình 3.5. Kiến thức về biểu hiện nhiễm độc chì ỏ triên
Bảng 3.4. Kiến thức về biện pháp phòng tránh nhiếm chi cho trẻ

\begin{tabular}{|c|c|c|c|c|c|c|}
\hline \multirow{2}{*}{ Biện pháp phòng tránh nhiễm chì cho trẻ } & \multicolumn{2}{|c|}{ NCST(n=165) } & \multicolumn{2}{|c|}{ Trẻ em $(n=47)$} & \multicolumn{2}{|c|}{ Chung( $(n=212)$} \\
\hline & $\mathbf{n}$ & $\%$ & $\mathbf{n}$ & $\%$ & $\mathbf{n}$ & $\%$ \\
\hline Giữ gìn vệ sinh cá nhân cho trẻ & 159 & 98,1 & 47 & 100 & 206 & 98,6 \\
\hline $\begin{array}{l}\text { Cho trẻ ăn đủ chất, nhất là các khoáng chất } \\
\text { như canxi, kêm, ... }\end{array}$ & 134 & 82,7 & 38 & 80,9 & 172 & 82,3 \\
\hline $\begin{array}{c}\text { Khi trẻ bị bệnh chỉ đưa trẻ đến khám tại các } \\
\text { cơ sở y tế có đăng ký }\end{array}$ & 88 & 54,3 & 21 & 44,7 & 109 & 52,2 \\
\hline Chỉ dùng các thuốc được lưu hành hợp pháp & 112 & 69,1 & 20 & 42,6 & 132 & 62,3 \\
\hline $\begin{array}{l}\text { Thận trọng tránh cho trẻ dùng những đồ chơ } \\
\text { có thể nhiếm chì }\end{array}$ & 153 & 92,7 & 43 & 91,5 & 196 & 93,8 \\
\hline Giữ vệ sinh môi trường & 152 & 93,8 & 44 & 93,6 & 196 & 93,8 \\
\hline Đảm bảo vệ sinh an toàn lao động & 125 & 77,2 & 39 & 83 & 164 & 78,5 \\
\hline Không biết & 3 & 1,8 & 0 & 0 & 3 & 1,4 \\
\hline
\end{tabular}

Bảng 3.4 cho thấy giữ vệ sinh cá nhân cho trẻ là biện pháp có tỷ lệ người lựa chọn nhiều nhất $98,6 \%$, tiếp đến là các biện pháp tránh cho trẻ dùng những đồ có thể nhiễm chì và giữ vệ sinh môi trường $(93,8 \%)$, cho trẻ ăn đủ chất, nhất là các khoáng chất như canxi, kẽm,... (82,3\%) và vẫn còn có $1,4 \%$ người tham gia không biết về các biện pháp phòng tránh nhiễm chì cho trẻ.

Những kiến thức về nhiễm độc chì ở trẻ em của người tham gia nghiên cứu được cung cấp từ các nguồn thông tin khác nhau. Trong 204 người cho biết nguồn thông tin mà họ đã tiếp cận, nguồn thông tin nhiều người tiếp cận nhiều nhất là ti vi $(73,0 \%)$; internet $(49,5 \%)$ và nhân viên y tế $(26 \%)$. Số người nhận được tờ rơi cung cấp thông tin về nhiễm độc chì cho trẻ chỉ chiếm tỷ lệ thấp dưới 1\% (Hình 3.6).

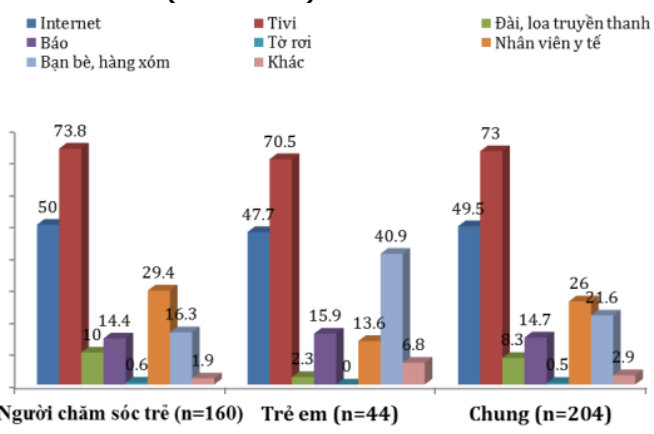

Hình 3.6. Nguồn cung cấp thông tîn về nhiễm độc chi ở trẻ 
Đánh giá chung kiến thức chung về phòng tránh nhiểm độc chì ở trẻ em của người tham gia nghiên cứu, kết quả cho thấy điểm kiến thức trung bình của nhóm người chăm sóc trẻ là $3,7 \pm 1,2$ điểm, của nhóm trẻ em 11-14 tuổi là $3,5 \pm 0,9$ điểm. Tỷ lệ NCST có kiến thức đạt chiếm $64,2 \%$, tỷ lệ này ở nhóm trẻ em 11-14 tuổi tham gia nghiên cứu là 46,8\% (Hình 3.7).

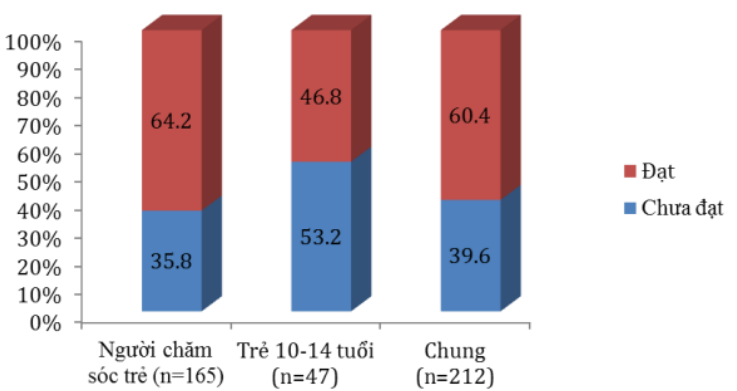

Hình 3. 7. Kiến thức chung về phòng tránh nhiếm độc chi cho tré em

\begin{tabular}{|c|c|c|}
\hline $\begin{array}{l}\text { Nhóm đối } \\
\text { tượng }\end{array}$ & $\begin{array}{l}\text { Điểm } \\
\text { trung bình } \\
\pm \text { Độ lệch } \\
\text { chuấn }\end{array}$ & $\begin{array}{c}\text { Điểm thấp } \\
\text { nhất - } \\
\text { Điểm cao } \\
\text { nhất }\end{array}$ \\
\hline $\begin{array}{l}\text { Người chăm sóc } \\
\text { trè }(n=165)\end{array}$ & $3,7 \pm 1,2$ & $0-6$ \\
\hline $\begin{array}{c}\text { Trẻ } 10-14 \text { tuối } \\
(n=47)\end{array}$ & $3,5 \pm 0,9$ & $2-6$ \\
\hline Chung $(n=212)$ & $3,6 \pm 1,1$ & $0-6$ \\
\hline
\end{tabular}

\section{BÀN LUÂN}

4.1. Đặc điểm đối tượng nghiên cứu. Nghiên cứu có sự tham gia của 212 đối tượng, trong đó $77,8 \%$ là NCST chính và $22,2 \%$ trẻ em từ 10-14 tuổi (nhóm trẻ em). Điều này phù hợp với thực tế điều tra tại địa bàn nghiên cứu, khi gửi giấy mời đến hộ gia đình, thường là cha/ mẹ hoặc NCST chính sẽ tham gia, tuy nhiên có một số gia đình có trẻ lớn 10-14 tuổi, do cha/ mẹ trẻ do không thu xếp được thời gian tham gia phỏng vấn, nên đã đồng ý cho trẻ tham gia nghiên cứu. Nhóm NCST tham gia nghiên cứu chủ yếu là nũ chiếm $89,1 \%$ cũng phù hợp với thực tế mẹ hoặc bà của trẻ thường là NCST chính.

4.2. Kiến thức về phòng tránh nhiễm độc chì cho trẻ em. Tỷ lệ người tham gia trả lời rằng trẻ em là đối tượng bị ảnh hưởng nhiều nhất khi bị nhiễm chì trong nghiên cứu tương đối cao $(91 \%)$. Kết quả này phù hợp với kiến thức của người dân nói chung đối với hầu hết các yếu tố có ảnh hưởng xấu đến sức khỏe con người thì trẻ em luôn là nhóm dễ bị tổn thương với lý do hệ miễn dịch chưa ổn đinh và còn non yếu.

Tuy nhiên, tỷ lệ liệt kê được trên 3 nguồn phơi nhiễm chưa cao $(25,2 \%)$ nhưng nhiều nguồn phơi nhiễm chì đã được các đối tượng tham gia nghiên cứu chỉ ra như thực phẩm chứa chì; sơn pha chì, nguồn nước, không khí bị ô nhiễm chì, hoạt động sản xuất, tái chế ắc quy và chất thải điện tử và đồ chơi có chứa chì. Những nguồn này đều năm trong những nguî̀n phơi nhiễm chính được WHO tổng kết [2]. Kết quả này cho thây những người tham gia nghiên cứu đã có một số kiến thức cơ bản về các nguồn phơi nhiễm chì cho trẻ.

Có 40,2\% người tham gia trả lời cho rằng trẻ trong gia đình không bị nhiễm chì. Kết quả này tương đồng với nghiên cứu của Mahon I (1997) tại Philadelphia với 49\% NCST chính không đề cập đến nhiễm độc chì như một mối quan tâm về sức khỏe mặc dù sống trong vùng có nguy cơ cao [3]; cao hơn tỷ lệ $11 \%$ trong tổng số 119 phụ nữ mang thai nhận biết được về nguy cơ nhiễm chì của bản thẩn trong nghiên cứu của Tanya Haman tại Bệnh viện Bà mẹ và trẻ em Rahima Moosa, Nam Phi [4].

Trả lời câu hỏi về con đường phơi nhiễm chì, đa số người tham gia trả lời lựa chọn con đường ăn, uống thức ăn, nước uống hoặc hít thở không khí bị ô nhiễm chì (90\%); tiếp đển là những thói quen không hợp vệ sinh của trẻ như ngậm, mút đồ chơi, đồ dùng và chơi lê la dưới sàn nhà, nền đất $(89,6 \%$ và $79,7 \%)$. Kết quả này tương ứng với câu trả lời của đối tượng về nguồn phơi nhiễm và tương đồng với kết quả nghiên cứu của Polivka BJ (1999) đánh giá kiến thức của cộng đồng nông thôn quận Ohio về phòng chống nhiểm độc chì [tham khảo qua 5].

Kết quả nghiên cứu cho thấy có tới $78,8 \%$ trong tổng số 212 người tham gia nghiên cứu không biết các biểu hiện nhiễm độc chì ở trẻ, cao hơn so với $58 \%$ tỷ lệ người trả lời sai câu hỏi kiến thức về biểu hiện sức khỏe của trẻ khi bị nhiễm độc chì trong nghiên cứu của James $R$. Roberts và cộng sự tại Mỹ năm 2012 [6].

Đối vời kiến thức về các biện pháp phòng tránh nhiễm độc chì cho trẻ, tỷ lệ người lựa chọn biện pháp giữ vệ sinh cá nhân cho trẻ, tránh cho trẻ dùng những đồ chơi có thể nhiễm chì, giữ vệ sinh môi trường và cho trẻ ăn đủ chất trong nghiên cứu (tương ứng là 98,6\%; 93,8\%; 93,8\% và $82,3 \%$ ) cao hớn so với nghiên cứu năm 2005 của tác giả Bustamante về kiến thức, thái độ và thực hành về phòng tránh nhiếm độc chì ở trẻ em Haiti với các tỷ lệ tương ứng là $88 \%$; 77\%; $72 \%$ và $72 \%$. [7].

Đa số người tham gia nghiên cứu biết được các thông tin về phòng tránh nhiễm độc chì cho 
trẻ chủ yếu qua ti vi $(73,0 \%)$ và internet $(49,5 \%)$, tỷ lệ nhận thông tin từ nhân viên y tê (26\%), nhận được tờ rơi cung cấp thông tin về nhiễm độc chì cho trẻ chỉ chiếm tỷ lệ thấp dưới $1 \%$. Kết quả này và phù hợp với sư triển của công nghệ thông tin hiện đại (đa số các hộ gia đình đều có ti vi và tiếp cận được internet). Tuy nhiên kết quả này cũng phản ánh rằng có thể tại Đa Hội chưa có hoặc ít triển khai hoặc triển khai chưa hiệu quả các hoạt động truyền thông về phòng chống nhiễm độc chì cho người dân. Đây có thể là lý do giải thích tại sao tỷ lệ người trả lời đúng các câu hỏi về kiển thức liên quan đến phòng tránh nhiễm độc chì cho trẻ trong nghiên cứu còn thấp.

\section{KẾT LUÂ̂N}

- Người dân tai môt làng nghề thuộc tỉnh Bắc Ninh đã có một số kiến thức cơ bản về phòng chống nhiễm độc chì cho trẻ nhưng còn hạn chế.

- Điểm kiến thức trung bình của nhóm người chăm sóc trẻ là $3,7 \pm 1,2$ điểm, của nhóm trẻ em 11-14 tuổi là 3,5 $\pm 0,9$ điểm. Tỷ lệ người chăm sóc trẻ có kiến thức đạt chiếm $64,2 \%$, tỷ lệ này ở nhóm trẻ em 11-14 tuổi tham gia nghiên cứu là 46,8\%.

\section{KHUYẾN NGH!}

Các tác giả khuyến nghị cần tăng cường triển khai các hoạt động truyền thông giáo dục sức khỏe dưới nhiều hình thức như tờ rơi, phát thanh trên loa, truyên thông trực tiếp tại trạm y tế và trường học, tư vấn/ giáo dục nhóm.... nhằm nâng cao kiến thức và thay đổi thái độ và thực hành về phòng tránh nhiễm độc chì cho trẻ em tại địa điểm nghiên cứu.

\section{TÀI LIẸU THAM KHẢO}

1. Moawad E.M., Badawy N.M. and Manawill M. (2016), "Environmental and Occupational Lead Exposure Among Children in Cairo, Egypt: A Community-Based Cross-Sectional Study", Medicine (Baltimore). 95(9).

2. WHO (2010), Childhood lead poisoning, WHO Document Production Services, Geneva, Switzerland.

3. Mahon I (1997), "Caregivers' knowledge and perceptions of preventing childhood lead poisoning", Public Health Nurs. 14(3), 169-182.

4. Tanya Haman, Angela Mathee and Andre Swart (2015), "Low Levels of Awareness of Lead Hazards among Pregnant Women in a High RiskJohannesburg Neighbourhood", Int J Environ Res Public Health. 12(12), 15022-15027.

5. Farrah Baara (2012), Best Practices for Lead Poisoning Prevention in Urban Bangkok Communities, Chulalongkorn University, Worcester Polytechnic Institute. (22)

6. James R. Roberts, et al. (2012), "Are Children Still at Risk for Lead Poisoning?", Clinical Pediatrics 52(2), 125-130.

7. Bustamante and Trepka Pekovic. V. (2005), "Haitian Caregivers' Knowledge and Attitudes Regarding Childhood Lead Poisoning", Miami-Dade County. 6.

\section{KẾT QUẢ SớM PHẪU THUẬT NộI SOI ĐIỀU TRỊ GIST DẠ DÀY TẠI BỆNH VIỆN K}

\section{TÓM TẮT}

Mục tiêu: Nghiên cứu này nhằm đánh giá kết quả sớm phẫu thuật nội soi điêu trị GIST da dày tạibệnh viên K. Phương pháp nghiên cứu: Hồi cứu mồ tả cắt ngang tất cả các bệnh nhân được chẩn đoán GIST da dày và điêu trị bằng phẩu thuật nội soi từ tháng 01/2018 đến tháng 12/2020. Kết quả: Có 37 bệnh nhân đủ tiêu chuẩn nghiên cứu với khối u kích thước từ 2 đến $9 \mathrm{~cm}$, trong đó 35 bệnh nhân $(94,6 \%)$ có giải phẩu bênh là u tế bào hình thoi, 2 bệnh nhân $(5,4 \%)$ giải phẫu bệnh u tế bào dạng biểu mô, thời gian mổ

${ }^{1}$ Trường Đại học Y Hà Nội

${ }^{2}$ Bềnh viện $K$

Chịu trách nhiệm chính: Hoàng Anh

Email: drhoanganh@hmu.edu.vn

Ngày nhận bài: 8.6.2021

Ngày phản biên khoa học: 30.7.2021

Ngày duyệt bài: 9.8 .2021
Hoàng Anh', Kim Văn Vụ̂, Phạm Trung Thông ${ }^{2}$, Nguyễn Tiến Trung ${ }^{2}$ trung bình $59,08 \pm 25,17$ phút, thời gian hậu phẫu

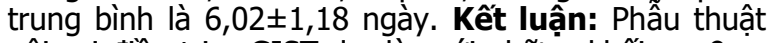
nội soi điều trị u GIST da dày với những khối u $<9 \mathrm{~cm}$ là an toàn, hiệu quả và có thể thực hiện ở những trung tâm lớn, phẫu thuật viên kinh nghiệm.

Tư khóa: Phẫu thuật nội soi điêu trị GIST dạ dày.

\section{SUMMARY}

\section{EARLY RESULTS OF LAPAROSCOPIC RESECTION OF GASTROINTESTINAL STROMAL IN K HOSPITAL}

Objectives: The aim of this study is to present initial results of laparoscopic resection of gastrointestinal stromal in K hospital. Methods: A retro-observational of all patients whom had been diagnosised GIST and treated by laparoscopic resection from 01/2018 to 12/2020. Results: 37 patients were identified whose tumor's size from 2 to $9 \mathrm{~cm}$, Histology study showed spindle in 35 patients $(94,6 \%)$ and epithelioid in 2 patients(5,4\%), medium 